\title{
Asphalt granulate coating for roadsides
}

\author{
Rustem Sakhapov ${ }^{1, *}$, Marat Makhmutov ${ }^{1}$, Regina Nikolaeva $^{1}$, and Muhammat Gatiatullin ${ }^{1}$ \\ ${ }^{1}$ Kazan state university of Architecture and Engineering, 1 Zelenaya St., Kazan, 420043, Russia
}

\begin{abstract}
The safety of road trains and other vehicles, the cost of maintenance and repair of roads largely depend on how well designed and calculated the design of the pavement. The research of many scientists and engineers is devoted to the design of pavement.

Quantitative and qualitative changes in traffic flows cannot but affect the actual condition of road pavement and coatings, as well as the requirements for their operational condition. Road clothing is a structure that includes several layers of different materials, the base of which is the ground of the roadbed.

The idea of deformability of the soil mass as a continuous homogeneous half-space has been developed for a long time and now continues to improve. Different technologies for the restoration of structural layers of the road surface were considered. On the basis of this work, it is possible to analyze the study of the state of roadsides and can be given suggestions for improving the calculation of the structures of their strengthening. As a result of the study, the reduction coefficients for the calculated vehicle were calculated with a different combination of longitudinal and transverse slopes of the roadway, a proportional increase in which will allow obtaining the reduction coefficients for all vehicles available in the flow, taking into account the slopes of the roadway.
\end{abstract}

\section{Introduction}

The method of calculating non-rigid elements of the road was firstly developed in 1870 by engineer E.S. Golovachev. The method of calculation he proposed was based on the assumption of an even distribution of pressure from the wheel of the vehicle into the clothing at an angle of the repose of the soil. Under this assumption, the area to which pressure is transmitted will increase as the pavement deepens into the thickness, which means that pressure distribution is a truncated cone, expanding deep into the road structure.

Knowing the value of the pressure distribution angle, which is assumed an average of $45^{\circ}$ for soils, it is possible to determine the area perceiving the load at any depth $\mathrm{z}$, and therefore, with a known load $\mathrm{p}$, set the specific pressure $\sigma_{z}$ in any section of the road pavement $\sigma_{\mathrm{z}}=\mathrm{p} / \omega_{\mathrm{z}}$. When calculating pavements by this method, the strength of soils is characterized only by the carrying capacity or their resistance to compression without taking into account such important factors as the elastic properties of clothing materials and underlying soils, the influence of the repetition of the loads applied.

\footnotetext{
* Corresponding author: rusakhapov@gmail.com
} 
The object of this study is asphalt granulate coating for the roadsides with a certain set of characteristics, and the goal is to develop methodology of calculating highways roadsides.

Research by professors N.N. Ivanova, N.M. Gersivanova and others identified the pattern of soils deformation under the load and developed theoretical foundations for calculating non-rigid pavements.

Road sections repair is often limited to the roadway due to the costs savings. The monitoring performed proved the importance of a more attentive attitude of road engineers to the construction, repair and maintenance of roadsides. Due to high transport loads, frequent use of the roadsides for parking and traffic, new building materials, it is essential to improve reinforced roadsides design methodology in terms of clarifying calculated humidity and, accordingly, the strength of the soil foundation.

Analysis of a number of scientists' researches (N.M. Kudryavtsev, V.I. Ruvinsky, E.I. Shelopaeva, V.N. Yefimenko and others) showed that the most preferred method for calculating the moisture of the road bed is the method of agricultural meteorological stations proposed by prof. V.M. Sidenko [10]. The method is based on the use of perennial spring observations of the open field soil moisture obtained at agrometeorological stations (AMS) of the region according to the standard methodology of the Hydrometeorological Service of the Russian Federation. Statistical series of maximum values of spring soil moisture at a depth of thermally equivalent to the road pavement are compiled for the AMS, which is located in this region and has similar ground and hydrological conditions with the projected road. The duration of statistical series is taken for the observation period, which is about 11 20 years or more. Based on the dependence of the soil moisture on the soil moisture of the open field, for the assumed reliability design moisture of the road pavement $\mathrm{W}_{\mathrm{p}}$ is calculated.

\section{Methodology}

In this paper, the following methodology has been applied:

1. Options for the road surface repair using asphalt granulate were considered.

2. Regulatory documents for the calculation of non-rigid pavements were adopted

a. Industry road standards IRD 218.046-01 "Design of non-rigid pavement."

b. GOST 32729-2014 Public roads. The method of measuring of elastic deflection of nonrigid pavements to determine the strength.

c. guidelines for assessing strength and calculating the strengthening of non-rigid pavements (DCR 52-89).

d. guidelines for improving the design of non-rigid type pavement .

3. Adjustment of the dynamic elastic moduli of asphalt concrete for different duration of loading is proposed.

4. Reduction coefficients for the estimated car with a different combination of longitudinal and transverse slopes of the roadway are calculated.

5. The calculations were summarized in Table 1 and 2.

For the calculation were used:

- $\quad$ relative moisture $\mathrm{W}$;

- $\quad$ calculated soil moisture Wp;

- $\quad$ density of clay soils Q;

- $\quad$ pressure by the load stamp P;

- $\quad$ angle of internal friction of the ground

- $\quad$ soil adhesion coefficient Kc;

- $\quad$ average traffic speed V;

- $\quad$ heating temperature of asphalt granulate Tc;

- $\quad$ heating temperature of the mineral part Tm; 
- $\quad$ elastic modulus E;

- $\quad$ reduction coefficients for a car with longitudinal and transverse slopes (table 2);

- $\quad$ equation coefficients (1-3) a, b и C.

Numerous studies have shown that it is possible to express the compressibility of the soil through the module of the total soil deformation. In this case, the modulus of deformation is similar to the modulus of elasticity, determined in accordance with the law of the theory of elasticity - Hooke's law — by the expression:

$$
\mathrm{E}=\mathrm{P} / \lambda, \mathrm{MPa}
$$

where $\lambda$ - is relative deformation,

$P$ - pressure by the load stamp.

Since the structural layers of non-rigid pavements are not linearly deformable bodies, the law of the theory of elasticity is applicable to the calculation of pavements with certain restrictions.

Emergency traffic, strength and evenness of the roadway, the speed of cars depend on the condition and width of the reinforced roadsides [1]. The following construction is applied when there is an intensive exposure of the subgrade to water (Fig. 1).
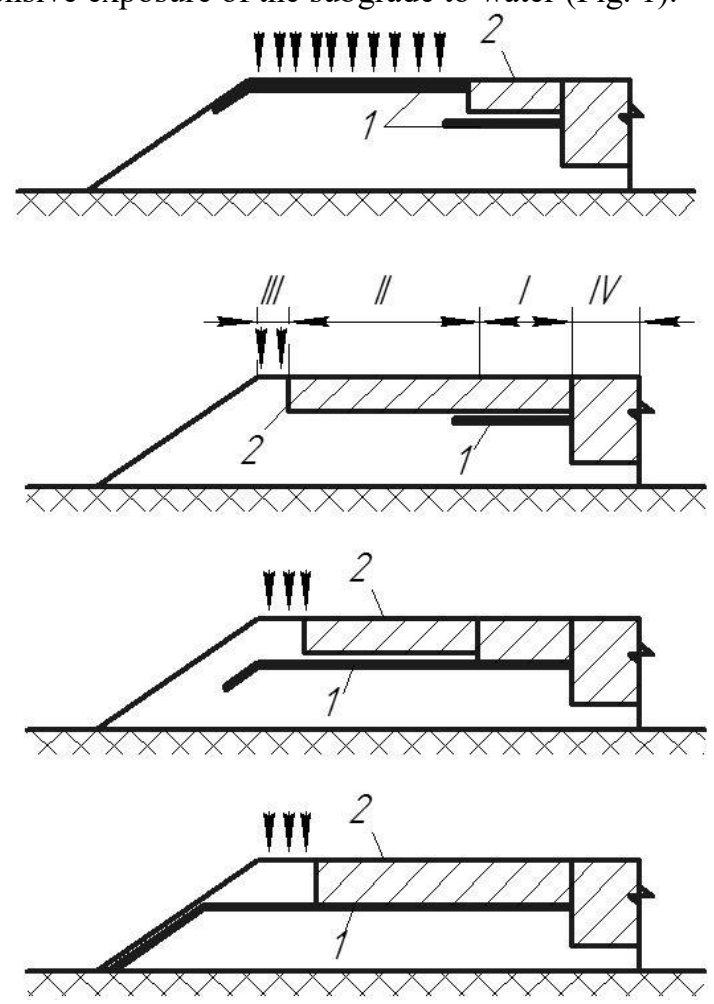

Fig. 1. The design of a reinforced pavement

Based on the processing of statistical data provided by V.M. Sidenko, A.M. Kameneva, O.T. Batrakova, Yu.A. Pokutnev and others, as well as the results of the survey of the roads in the Republic of Tatarstan, the complex effect of the relative humidity $\mathrm{W}$ and the density Ky of clay soils on their strength characteristics [8] was established, namely:

- modulus of soil elasticity:

$$
\mathrm{E}=\frac{\mathrm{C} \cdot Q^{1,5}}{W^{a}}, \mathrm{MPa}
$$

- soil adhesion: 
- $\quad$ soil friction angle:

$$
\mathrm{C}=\frac{\mathrm{C} \cdot Q^{1,5}}{W^{a}}, \mathrm{kPa}
$$

$$
\varphi=\mathrm{C}+\mathrm{a} \cdot \mathrm{Q}+\mathrm{b} \cdot \mathrm{W} . \quad 0
$$

Modern regulations are very progressive compared to the previously existing ones, as the required modulus of elasticity is now prescribed on the basis of the total number of applications of the calculated load over the life of the pavement. However, the contribution of a single load application, depending on its duration, and ultimately on the average speed of the traffic flow, is not actually taken into account. Formally, the duration of the load is taken into account in terms of the dynamic elastic moduli of the materials of the layers and is $0.1 \mathrm{~s}$, which does not quite correspond to the actual duration of the loading of the structure. This is mentioned in the researches of A.M. Boguslavsky, B.S. Radovsky, A.V. Rudensky, A.V. Smirnova, Yu.M. Yakovlev, P.P. Petrovich, N.A. Tsytovich [12].

\begin{tabular}{|c|c|c|c|c|c|c|}
\hline \multirow{2}{*}{$\begin{array}{l}\text { Soil strength } \\
\text { characteristics }\end{array}$} & \multirow[b]{2}{*}{ Soil type } & \multirow{2}{*}{$\begin{array}{l}\text { Standard } \\
\text { error }\end{array}$} & \multirow{2}{*}{$\begin{array}{c}\text { Multiple } \\
\text { correlation } \\
\text { coefficient }\end{array}$} & \multicolumn{3}{|c|}{ Values of the equations } \\
\hline & & & & $\mathrm{C}$ & $\mathrm{a}$ & $\mathrm{b}$ \\
\hline \multirow{2}{*}{ Elastic modulus } & $\begin{array}{l}\text { Loam and } \\
\text { clay }\end{array}$ & 0,021 & 0,98 & 2,879 & 3,158 & \\
\hline & sandy loam & 0,021 & 0,98 & 4,234 & 0,234 & \\
\hline \multirow[t]{2}{*}{$\begin{array}{l}\text { Angle of internal } \\
\text { friction }\end{array}$} & $\begin{array}{l}\text { Loam and } \\
\text { clay, silty } \\
\text { dust }\end{array}$ & 0,055 & 0,97 & 0,099 & 3,431 & \\
\hline & sandy loam & 0,018 & 0,97 & 0,117 & 0,926 & \\
\hline \multirow[t]{2}{*}{ Soil adhesion } & $\begin{array}{l}\text { Loam and } \\
\text { clay, silty } \\
\text { dust }\end{array}$ & 0,328 & 0,98 & 40,029 & 19,045 & $-59,303$ \\
\hline & sandy loam & 0,082 & 0,98 & 10,014 & 34,654 & $-14,835$ \\
\hline
\end{tabular}

Table 1. The coefficients of equations (1-3)

Taking into account the theoretical prerequisites [3-4], the authors of the article propose an adjustment of the dynamic elastic moduli of asphalt concrete for different durations of loading, which will make it possible to approach real conditions at the design stage of the road pavement.

\section{Calculation results and discussion}

Based on theoretical studies, authors of the article calculated the reduction coefficients for a design car with a different combination of longitudinal and transverse slopes of the roadway (Table 1), a proportional increase of which will allow obtaining the reduction coefficients for all vehicles present in the flow, taking into account the slopes of the roadway .

Existing instructions for the design of non-rigid pavement provides calculation of several criteria in order to fully consider all the factors affecting the road construction. But neither norms nor DCR 46-83 (DCR 46-72) have a clear algorithm for calculating pavements, the most significant parameters affecting the compliance with one or another calculation criterion are not evaluated, and the values of the minimum thickness of structural layers are not justified. Thus, often a design that satisfies any criterion (for example, elastic deflection) does not satisfy another (for example, the resistance of monolithic layers to fatigue failure due to bending stretching), so the engineer has to change the thickness of structural layers, which leads to continuous repetition of the entire calculation procedure. This is very time consuming 
and often leads to material waste, since any change in the thickness of a single structural layer influences the mechanical properties of the whole road structure [9].

The calculated soil moisture of natural occurrence is determined by the formula:

$$
\mathrm{W}_{\mathrm{p}}^{\mathrm{on}}=\mathrm{W}_{\mathrm{av}} \cdot\left(1+\mathrm{t} \cdot \mathrm{C}_{\mathrm{v}}\right) \text {, }
$$

where $W_{a v}$-average modal value of relative soil moisture,

$\mathrm{t}$ - unilateral normalized deviation depending on the accepted level of reliability.

One of the effective solutions for non-rigid elements of roads reinforcement is the use of asphalt granulates and putting its additional layers to strengthen the roadsides. The paving of the road pavement on the edge lanes and on the roadsides (Fig. 2) was carried out by a single pass dredging machine D-391.

$10-15 \mathrm{~cm}$ excess of the edge of the roadway above the curb surface in the repair of the road (Fig. 3) causes traffic accidents.
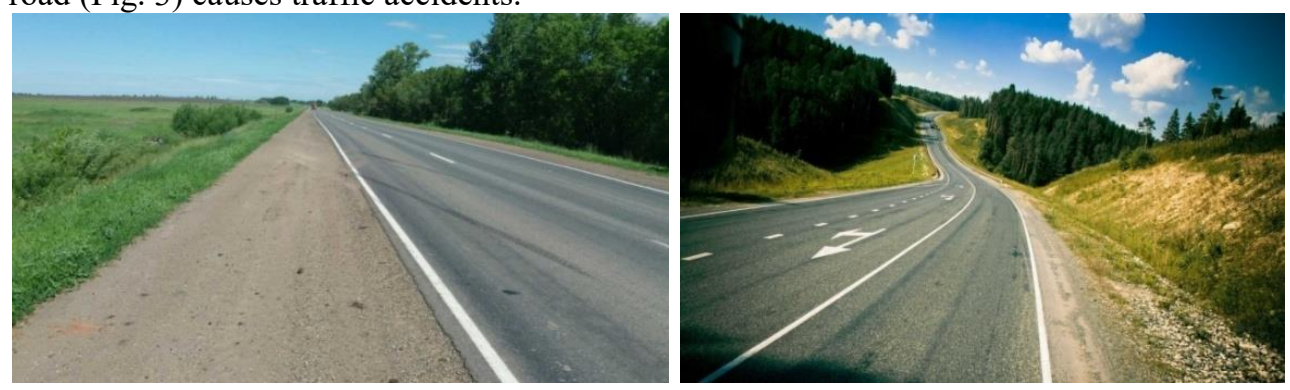

Fig. 2. The use of roadsides for the movement of vehicles in Kazan

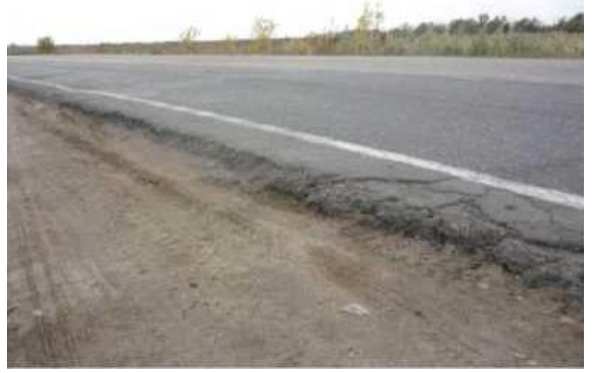

Fig. 3. The excess of the edge of the road pavement over the curb



Fig. 4. Ready asphalt granulate

Currently, the United States, England, Germany and France, Japan, and Czech Republic reuse asphalt concrete (Fig. 4), it is relevant in the repair of the pavements, due to the sharp increase in prices for bitumen and other components of asphalt concrete. Regeneration at an asphalt concrete plant saves money and materials by $15-20 \%$. 
The results of many years of research $[1,7]$ show that in the processed asphalt concrete there are minerals containing an asphalt binder film on the surface.

Road industry enterprises in a number of regions of Russian Federation have established the production of asphalt granulate (AG). In the United States, it is believed that with $100 \%$ consideration of all circumstances, it is allowed to use up to $70 \%$ of $A G$ in the asphalt mix $[3,6]$. In our country, the experience of using asphalt granulate is not as wide as abroad [6].

The results of experimental construction with asphalt granulate $[1,2]$ are made according to the methodological recommendations [5].

When calculating the structure of the reinforcement, data on the strength characteristics of asphalt concrete [13] was applied. Statistical data processing allowed determining the calculated values of the elastic modulus $E$ taking into account the temperature [14].

On the basis of experimental data, dependence was obtained for calculating the temperature of heating of the mineral part $\mathrm{T}_{\mathrm{m}}$ :

$$
\mathrm{T}_{\mathrm{m}}=4,8 \cdot \mathrm{T}_{\mathrm{c}} \mathrm{T}^{0,9} \cdot \mathrm{a}^{0,3} \cdot \mathrm{W}^{0,02}
$$

where $\mathrm{W}-$ is moisture content of the original mineral part of asphalt granulate.

The resulting mixture is delivered to the site by trucks. In order to avoid hardening of the mixture, the delivery time should not exceed 2 hours. It is possible to distribute the mixture on the side of the road with an auto grader. Compaction is carried out with a smooth roller with a mass of 10 tons with 10 passes along the track. Rolling continues till full compaction is achieved.



Fig. 5. Dependence of tensile strength on the elastic modulus of the material

\section{Conclusions}

As a result of the study it was found:

1. Calculation of pavement according to the criterion for ensuring the stability of the layers of slightly connected materials and the underlying soil of the road bed is expedient when the total movement is less than $1 \cdot 106$; with a larger total motion, the calculation according to the criteria discussed above achieves a design that obviously satisfies the criterion under consideration.

2. Calculation of the design according to the criterion for ensuring the stability of the underlying soil of the roadbed is necessary if the working layer contains soils of the III$\mathrm{V}$ group according to the degree of heaving of moisture with more than 0.75 from the yield limit.

The coating of asphalt granulate by the method of displacement with liquid bitumen or cement on the object is carried out at air temperatures from -5 to $+10^{\circ} \mathrm{C}$. AGB is distributed by a motor grader with a thickness of at least $4 \mathrm{~cm}$ along a primed base with tacking with a smooth-drum roller. The final formation of a durable structure of the material occurs within 
8-10 days of warm weather during the reverse impregnation of AG with a binder. After this period, the final compaction of asphalt granulate with a smooth-roller weighing 10 tons is recommended. When repairing the roadsides, the use of asphalt granulate reduces the cost to 140 rubles per square meter of the road.

\section{References}

1. S.V. Aleksikov, A.N. Badrutdinov, Vestnik VolGU, 7, 40-45 (2012)

2. S.V. Aleksikov, A.A. Ermilov, Vestnik VolGU, 7, 102-145 (2013)

3. A.I. Brehman, R.L. Sahapov, S.G. Absaljamova, Nauka i tehnika v dorozhnoj otrasli, 3(69), 39-41 (2014)

4. T.N. Kalashnikov, M.B. Sokalskaya, Production asphalt concrete of mixes (EKON, Moscow, 2001)

5. Ministry of Transportation of Russian Federation, Methodical recommendations about repair of asphalt concrete coverings and bases of highways in the ways of cold regeneration (Rosdorniya, Moscow, 2002)

6. The guide to construction of pavings from hot asphalt concrete (Ohio, Cincinnati, 1993)

7. R.L. Sakhapov, M.M. Makhmutov, Izvestiya Samarskogo nauchnogo chentra RAN, 17, № 2(4), 896-899 (2015)

8. R.L. Sakhapov, M.M. Makhmutov, Izvestiya KGASU, 4(30), 497-502 (2014)

9. R.L. Sakhapov, M.M. Makhmutov, Izvestiya KGASU, 2, 289-294 (2015)

10. V.M. Sidenko Calculation and regulation of the water and thermal mode of road clothes and road bed (Avtotransizdat, Moscow, 1962)

11. G.K. Syun, K.H. Usmanov, E.S. Faynberg The regenerated road asphalt concrete (Transport, Moscow, 1984)

12. N.A. Tsytovich Questions of the theory and practice of construction on soft clay soils, Materials of the All-Union meeting on construction on soft clay soils, Tallinn (1965)

13. R.L. Sakhapov, R.V. Nikolaeva, M.H. Gatiyatullin, M.M. Makhmutov J. Phys.: Conf. Ser., 738, 012119 (2016)

14. R.L. Sakhapov, R.V. Nikolaeva, M.H. Gatiyatullin, M.M. Makhmutov, J. Phys.: Conf. Ser., 738, 012008 (2016) 